\title{
ANALISIS PENGARUH FINANCIAL INDICATORS DAN OWNERSHIP STRUCTURE UNTUK MEMPREDIKSI KONDISI FINANCIAL DISTRESS (STUDI PADA SEKTOR INDUSTRI PERDAGANGAN, JASA, DAN INVESTASI YANG TERDAFTAR DI BEI TAHUN 2014-2018)
}

\author{
Elyia Rosiana Savitri \\ Universitas Negeri Surabaya \\ elyiarosianasav@gmail.com \\ Purwohandoko Purwohandoko \\ Universitas Negeri Surabaya \\ purwohandoko@unesa.ac.id
}

\begin{abstract}
Financial distress is the stage when a company experiences a decline in financial performance before bankruptcy occurs. This study aims to examine the effect of financial indicators and ownership structure on financial distress. The independent variables in financial indicators include profitability, activity, growth, liquidity, and leverage. The ownership structure includes managerial ownership and institutional ownership. This research period is for five years, from 2014 to 2018. This study's population are companies in the trade, services, and investment sectors. Samples were taken using the purposive sampling method and obtained 16 companies as samples. The results of data analysis using the logistic regression method. The results showed that the current ratio and debt to assets ratio significantly affected financial distress. Meanwhile, the variables return on assets, total assets turnover, sales growth, managerial ownership, and institutional ownership do not significantly affect financial distress. The solution that the trade, service can carry out, and investment industry sector that has negative EPS in a row is to pay off short-term obligations within a predetermined period and maximize the benefits of debt as a tax deduction so that financial distress for companies can be avoided.
\end{abstract}

Keywords: financial distress; financial indicator; ownership structure

\section{PENDAHULUAN}

Ketidakpastian kondisi ekonomi dunia yang meningkat ditandai dengan siklus suku bunga yang tinggi dari tiap periode serta ketidakpastian keadaan pasar keuangan global mengakibatkan eskalasi ekonomi global 2018 melemah (Bank Indonesia, 2018). Hal ini mengakibatkan eskalasi ekonomi Indonesia pada 2018 melambat sebesar $5.17 \%$, jumlah persentase tersebut lebih tinggi dari tahun 2017 sebesar 5.07\%, eskalasi 5.17\% merupakan yang tertinggi sejak 2013, namun tahun 2015 tercatat $4.88 \%$ eskalasi terendah selama 8 tahun terakhir (Setkab.go.id, 2019). Data persentase tingkat eskalasi tersebut menyatakan eskalasi ekonomi Indonesia melambat dan memberikan dampak yang kurang baik terhadap perusahaan khususnya kinerja keuangan (Masita \& Purwohandoko, 2020).

Penurunan kondisi keuangan perusahaan dalam jangka waktu tertentu sebelum terjadi kebangkrutan maka perusahaan dalam kondisi financial distress (Ananto, 2020). Perusahaan yang tidak efektif dalam mengelola, menjaga, dan mempertahankan kinerja keuangannya dapat dilihat dari ketidakmampuan perusahaan dalam mengoperasikan bisnisnya sehingga penjualan dan pendapatan menurun yang berdampak pada kerugian bersih dan operasional (Liu et al., 2021). Apabila hal tersebut tidak segera diatasi maka kebangkrutan perusahaan akan terjadi. Earning per share negatif menunjukkan perusahaan dalam kondisi financial distress (Restianti \& Agustina, 2018). Data daftar perusahaan per sektor yang tercatat memiliki earning per share negatif tahun 2014-2018 disajikan pada gambar 1. 
Elyia Rosiana Savitri \& Purwohandoko Purwohandoko. Analisis Pengaruh Financial Indicators dan Ownership Structure untuk Memprediksi Kondisi Financial Distress (Studi pada Sektor Industri Perdagangan, Jasa, dan Investasi yang Terdaftar di BEI Tahun 2014-2018

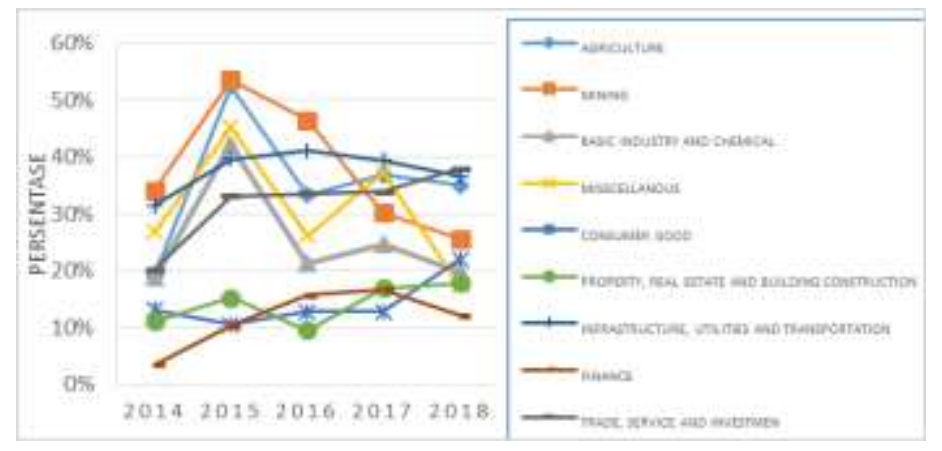

Sumber: $\underline{\text { idx.co.id }}$ (2021), data diolah.

\section{Gambar 1. PERSENTASE EPS NEGATIF PER SEKTOR}

Berdasarkan gambar 1, tingkat pertumbuhan EPS negatif sektor industri tercatat di BEI tahun 20142018. Sektor industri yang memiliki nilai pertumbuhan EPS negatif berturut-turut tiap tahunnya adalah sektor perdagangan, jasa, dan investasi. Keuntungan yang diperoleh sektor tersebut menurun dalam kurun waktu 2014-2018 dan berpotensi mengalami financial distress.

Financial distress memengaruhi perusahaan besar maupun perusahaan kecil serta terdapat aspek yang dapat menyebabkan perusahaan mengalami kesulitan keuangan salah satunya yaitu aspek internal (Nugrahanti et al., 2020). Menurut Jiming \& Weiwei (2011), aspek internal perusahaan dapat dilihat melalui financial indicators yaitu rasio profitabilitas, aktivitas, sales growth, likuiditas, dan leverage yang dapat memberikan informasi menganai internal perusahaan sabagai prediksi kondisi kinerja keuangan perusahaan pada saat ini dan di masa mendatang.

Rasio profitabilitas dapat diartikan sebagai kemampuan perusahaan dalam mengelola biaya untuk mendapatkan keuntungan yang maksimal (Dirman, 2020). Pengelolaan aset yang efektif dapat menambah keuntungan bagi perusahaan, yaitu dengan memaksimalkan perolehan laba dan meminimalkan kerugian kompetitif (Deandrés et al., 2009). Return on assets (ROA) merupakan gambaran rasio penelitian ini. Fungsi ROA sebagai pengukuran kapasitas perusahaan untuk mendapatkan keuntungan melalui penggunaan semua aset perusahaan (Sudana, 2011). Muis (2017) membuktikan ROA memiliki dampak positif dengan financial distress. Namun, menurut Rizkyana et al. (2021) ROA tidak memiliki dampak dengan financial distress.

Rasio aktivitas dimanfaatkan sebagai penilaian keefektifan perusahaan dalam mengoperasikan aset dan seluruh sumber daya yang dimilikinya (Kasmir, 2016). Total assets turnover (TATO) merupakan gambaran rasio penelitian ini. Penggunaan TATO dimaksudkan sebagai pengukuran semua aktiva dengan seluruh aset yang dimiliki perusahaan dan kapasitas penjualan pada tiap tahunnya (Kasmir, 2016). Kapasitas aset yang banyak mengakibatkan perusahaan kurang efektif dalam menghasilkan penjualan sehingga pendapatan yang diperoleh berkurang dan mengakibatkan terjadinya kesulitan keuangan (Arini et al., 2021). Restianti \& Agustina (2018) membuktikan TATO tidak memiliki dampak dengan financial distress. Perbedan dengan Diwanti \& Purwanto (2020) dan Restianti \& Agustina (2018) TATO berpengaruh negatif terhadap financial distress.

Rasio sales growth menunjukkan kesanggupan perusahaan dalam mengatur pertumbuhan penjualannya (Kasmir, 2016). Apabila pertumbuhan penjualan meningkat dari tahun sebelumnya dan laba yang diperoleh perusahaan semakin tinggi, maka dapat dikatakan strategi manajemen perusahaan berjalan dengan baik (Dianova \& Nahumury, 2019). Sudjiman \& Sudjiman (2020) mengemukakan sales growth tidak berpengaruh pada financial distress. Sedangkan Alifah \& Trisilo (2021) menunjukkan adanya pengaruh negatif sales growth dengan financial distress.

Rasio likuiditas memiliki arti kecakapan perusahaan untuk membayar utang finansialnya dengan jangka waktu pendek yang ditetapkan serta menggunakan proksi current ratio sebagai pengukuran 
kemampuan perusahaan dalam melunasi utangnya secara tepat waktu (Lumbantobing, 2020). Oktasari (2020) membuktikan current ratio berpengaruh positif dengan financial distress. Najwa (2020) mengemukakan dampak negatif current ratio dengan financial distress. Namun, Sugiarto \& Mahanani (2020) memerlihatkan current ratio tidak berpengaruh terhadap financial distress.

Rasio leverage menunjukkan besarnya total aset yang dibiayai oleh utang dengan menggunakan gambaran debt to assets ratio (DAR) yang digunakan sebagai perhitungan jumlah total aset melalui penggunaan utang jangka panjang dan pendek (Kasmir, 2016). Sugiarto \& Mahanani (2020) membuktikan adanya pengaruh positif DAR dengan financial distress. Muis (2017) memerlihatkan DAR tidak berdampak pada financial distress.

Faktor internal lainnya dalam memprediksi kesulitan keuangan adalah ownership structure yaitu managerial ownership dan institutonal ownership. Managerial ownership yaitu kapasitas saham direksi perusahaan yang memiliki peran aktif untuk mengambil keputusan perusahaan (Juliana Lelu \& Thamrin, 2021). Md-Rus et al. (2013) menunjukkan managerial ownership tidak berpengaruh dengan financial distress. Sedangkan Anggriani \& Rahim (2021) menunjukkan managerial ownership memiliki dampak positif terhadap financial distress.

Institutional ownership yaitu kapasitas saham yang dimiliki lembaga dan badan usaha yang meliputi bank, perusahaan asuransi, dan reksadana (Kabir et al., 2020). Syofyan \& Herawaty (2019) membuktikan institutional ownership berpengaruh negatif pada financial distress. Sedangkan Liahmad et al. (2021) membuktikan tidak adanya pengaruh institutional ownership pada financial distress.

Berdasarkan latar belakang yang dipaparkan, tujuan riset ini adalah untuk mengetahui pengaruh financial indicators dan ownership structure dalam memprediksi kondisi financial distress pada sektor industri perdagangan, jasa, dan investasi yang terdaftar di BEI tahun 2014-2018.

\section{KAJIAN PUSTAKA DAN PENGEMBANGAN HIPOTESIS}

\section{Du Pont Theory}

Du pont theory merupakan analisis yang digunakan untuk mengkaji hubungan total pendapatan, total aset, dan utang sebagai cerminan untuk mendapatkan informasi kinerja keuangan perusahaan (Sudana, 2011:25). Terdapat 3 komponen rasio pengembalian atas ekuitas yang dipaparkan oleh $d u$ pont theory yaitu evaluasi manajemen aset, manajemen biaya, dan manajemen utang, kinerja keuangan perusahaan menunjukkan hasil yang maksimal apabila komponen tersebut dapat dikelola dengan baik (Dipietre et al., 1997). Analisis du pont memiliki keunggulan yaitu dapat memaksimalkan pengukuran efisiensi modal, produksi, dan penjualan sehingga dapat diketahui kondisi kinerja keuangan perusahaan (Prianto \& Amboningtyas, 2017).

\section{Trade Off Theory}

Trade off theory memberikan informasi mengenai tindakan perusahaan dalam mengelola keseimbangan antara manfaat dan risiko potensi kebangkrutan melalui pendanaan yang ditentukan oleh komposisi ekuitas dan nilai utang (Modigliani \& Miller, 1958). Apabila terjadi keseimbangan antara manfaat dan risiko potensi kebangkrutan maka pemakaian liabilitas dikatakan optimal apabila perusahaan hanya mengandalkan ekuitas maupun nilai utangnya saja, maka risiko gagal bayar perusahaan dapat terjadi (Elkamhi et al., 2012).

\section{Agency Theory}

Agency theory menjelaskan mengenai perbedaan kepentingan yang saling bertentangan antara manajer (agent) dan pemilik perusahaan (principal) yang dapat berpotensi menimbulkan konflik (Jensen \& Meckling, 1976). Apabila manajer memiliki tujuan dan kepentingan yang berbeda dengan pemilik perusahaan, maka pemilik perusahaan harus mengatasi perbedaan tujuan dan kepentingan tersebut dengan memberikan biaya insentif, monitoring secara berkala, dan melakukan penunjukan 
Elyia Rosiana Savitri \& Purwohandoko Purwohandoko. Analisis Pengaruh Financial Indicators dan Ownership Structure untuk Memprediksi Kondisi Financial Distress (Studi pada Sektor Industri Perdagangan, Jasa, dan Investasi yang Terdaftar di BEI Tahun 2014-2018

komisaris independen dan upaya untuk mengatasi perbedaan kepentingan dapat menimbulkan biaya agen atau beban biaya yang wajib dibayar untuk mengganti kerugian manajer (Baklouti et al., 2016).

\title{
Financial Distress
}

Financial distress menunjukkan keadaan perusahaan pada fase penurunan keuangan tahap akhir sebelum mengalami likuidasi yang dapat dilihat melalui dua kondisi yaitu kesulitan dalam memenuhi kewajiban jangka pendek dan kondisi menuju kebangkrutan (Ananto, 2020). Kesulitan keuangan dalam memenuhi kewajiban jangka pendek bersifat sementara, namun bisa menuju kebangkrutan apabila tidak segera diatasi dengan baik atau utang perusahaan cenderung naik dari aset yang dimiliki perusahaan, hal tersebut mengindikasikan suatu perusahaan cenderung mengalami kebangkrutan (Mamduh \& Abdul, 2016). Oleh karena itu, untuk mencegah hal tersebut terjadi perusahaan harus menyelesaikan kewajiban jangka pendeknya seperti membayar pajak dan upah karyawan.

Metode Altman Z-Score digunakan sebagai pengukuran kesulitan keuangan perusahaan dengan menggabungkan rasio keuangan dan memberikan bobot yang tidak sama antara satu perusahaan dengan yang lain (Grice \& Ingram, 2001). Persamaaan metode Altman Z-Score pada rumus (1).

$$
\mathrm{Z}=6.56 \chi^{1}+3.26 \chi^{2}+6.72 \chi^{3}+1.05 \chi^{4}
$$

Keterangan:

$\mathrm{X}^{1} \quad=$ Working Capital to Total Assets Ratio

$\mathrm{X}^{2} \quad=$ Retained Earnings to Total Assets

$\mathrm{X}^{3}=$ Earnings Before Interest and Taxes to Total Assets

$\mathrm{X}^{4} \quad=$ Market Value of Equity to Book Value of Liabilities

Kategori penentuan Altman Z-Score apabila perusahaan dengan kondisi financial distress ditandai satu (1) dengan perolehan $Z<1.1$ dan perusahaan dengan kondisi non financial distress ditandai nol (0) dengan perolehan $Z>1.1$ (Sagho \& Merkusiwati, 2015).

\section{Profitabilitas}

Rasio profitabilitas digunakan sebagai penilaian kecakapan perusahaan dalam menghasilkan laba perusahaan melalui hasil perdagangan produk dan penghasilan dari investasi (Kasmir, 2016). Rasio profitabilitas dihitung dengan return on assets, proksi ini dimanfaatkan sebagai pengukuran kecakapan perusahaan dalam memeroleh laba bersih berdasarkan pemanfaatan aset milik perusahaan (Sudana, 2011). ROA dengan angka tinggi menunjukkan efektivitas manajemen dalam mengelola investasinya. Perhitungan ROA dapat dilihat dengan rumus (2).

Return on assets $=\frac{E B I T}{\text { Total assets }}$

\begin{abstract}
Aktivitas
Menurut Kasmir (2016) rasio aktivitas digunakan sebagai pengukuran efektivitas pengelolaan sumber daya dan aset perusahaan. Perhitungan rasio aktivitas menggunakan total assets turnover yang digunakan sebagai pengukuran efektivitas perusahaan dalam mengelola sumber daya berupa aktiva milik perusahaan (Noviandri, 2014). TATO yang tinggi menunjukkan pemanfaatan aset yang efisien dan pemulihan anggaran dalam bentuk tunai akan cepat. TATO dihitung menggunakan rumus (3).
\end{abstract}

Total Assets Turnover $=\frac{\text { Sales }}{\text { Total assets }}$

\section{Sales growth}

Sales growth adalah kecakapan perusahaan dalam melindungi kondisi ekonominya pada situasi pertumbuhan ekonomi dan sektor usahanya yang dihitung dengan melihat pertumbuhan penjualan, laba bersih, dan dividen per saham (Kasmir, 2016). Sales growth dihitung menggunakan rumus (4). 


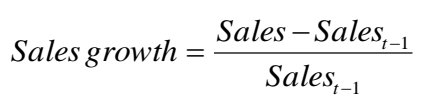

\section{Likuiditas}

Rasio likuiditas digunakan sebagai perhitungan kecakapan perusahaan melunasi utang finansialnya dengan waktu yang telah ditetapkan (Kasmir, 2016). Current ratio adalah gambaran rasio ini, yaitu perbandingan antara aset lancar dengan utang lancar. Current ratio dihitung dengan rumus (5).

Currentratio $=\frac{\text { Current Assets }}{\text { Current Liabilities }}$

\section{Leverage}

Menurut Kasmir (2016) rasio leverage digunakan untuk mengukur jumlah aset pembiayaan utang. Artinya, seberapa besar kapasitas utang yang dibebankan dari total aset perusahaan. Perhitungan rasio leverage adalah dengan menggunakan debt to assets ratio yaitu pengukuran perbandingan antara total utang perusahaan dengan total asetnya. Rumus perhitungan DAR yaitu (6).

Debtto Assets Ratio $=\frac{\text { Total Liabilities }}{\text { Total Assets }}$

\section{Managerial Ownership}

Managerial ownership adalah kapasitas kepemilikan oleh manajer atau direksi perusahaan (Nurbaiti et al., 2021). Kepemilikan saham oleh internal perusahaan dapat memberikan nilai tambah bagi perusahaan, karena manajer sebagai pemilik dan pengelola saham akan menanggung semua risiko dan keputusan yang akan diambil perusahaan (Kabir et al., 2020). Keadaan tersebut membuat manajer dan pimpinan perusahaan untuk lebih termotivasi dalam meningkatkan kinerja perusahaan. Rumus managerial ownership pada persamaan (7).

$$
M A N_{\text {Ow }}=\frac{\text { Managerial } \text { Ownership }}{\text { Total sahamberedar }} \times 100 \%
$$

\section{Institutional Ownership}

Institutional ownership yaitu kapasitas saham yang dimiliki oleh lembaga tidak termasuk bank antara lain reksadana, dana pensiun, dan perusahaan asuransi (Handriani et al., 2021). Institutional ownership dapat mengurangi biaya keagenan karena kapasitas institutional ownership yang lebih tinggi akan membuat investor memberikan pengarahan yang lebih konvensional sehingga manajer diharapkan harus berhati-hati dalam membuat keputusan penting mengenai investasi dan operasional perusahaan (Guo \& Platikanov, 2019). Perhitungan institutional ownership pada rumus (8).

$$
I N S_{\text {OWN }}=\frac{\text { Institutional } \text { wnership }}{\text { Total sahamberedar }} \times 100 \%
$$

\section{Hubungan antar Variabel}

Return on assets menggambarkan bagaimana kecakapan perusahaan dalam memeroleh laba (Kasmir, 2016). Perusahaan dengan nilai ROA tinggi dapat dikatakan bahwa pengelolaan aset perusahaan dapat dikelola dengan baik, hal tersebut menunjukkan kinerja keuangan berjalan dengan lancar dan dapat memeroleh laba dengan maksimal sehingga perusahaan terlepas dari kemungkinan kondisi financial distress, sedangkan perusahaan dengan nilai ROA rendah maka pengelolaan aset tidak efektif, sehingga menyebabkan penurunan laba perusahaan dan kinerja keuangan juga menurun maka perusahaan dikatakan mengalami financial distress (Deandrés et al., 2009).

H1: Ada pengaruh positif signifikan return on assets terhadap financial distress. 
Elyia Rosiana Savitri \& Purwohandoko Purwohandoko. Analisis Pengaruh Financial Indicators dan Ownership Structure untuk Memprediksi Kondisi Financial Distress (Studi pada Sektor Industri Perdagangan, Jasa, dan Investasi yang Terdaftar di BEI Tahun 2014-2018

Total assets turnover digunakan sebagai pengukuran efektivitas perusahaan dalam mengelola aset keseluruhan (Kasmir, 2016). Perusahaan yang memiliki nilai TATO tinggi dapat dikatakan bahwa penggunaan aset perusahaan dapat dikelola dengan baik, sehingga pengembalian dana dapat maksimal dan perusahaan dapat menghindari kemungkinan financial distress, namun apabila nilai TATO perusahaan rendah menunjukkan penggunaan aset kurang efisien, sehingga pengembalian dana akan menurun yang mengakibatkan perusahaan terancam mengalami financial distress (Noviandri, 2014).

\section{H2: Ada pengaruh positif signifikan total assets turnover terhadap financial distress.}

Sales growth menunjukkan perusahaan memiliki kemampuan untuk meningkatkan kapasitas penjualannya (Kasmir, 2016). Semakin tinggi rasio ini artinya pertumbuhan penjualan semakin meningkat dan perusahaan dalam kondisi yang baik dan dapat terhindar dari kondisi financial distress, sebaliknya rasio yang rendah menggambarkan penjualan pada perusahaan mengalami penurunan sehingga pendapatan yang dihasilkan perusahaan berkurang dan akan berdampak terjadinya financial distress (Prayuningsih et al., 2021).

\section{H3: Ada pengaruh positif signifikan sales growth terhadap financial distress.}

Current ratio menggambarkan perhitungan kecakapan perusahaan untuk melunasi semua utang jangka pendeknya (Kasmir, 2016). Apabila perusahaan bisa memenuhi utangnya sesuai dengan jangka waktu yang ditentukan dapat dikatakan perusahaan tersebut terhindar dari financial distress, namun apabila perusahaan kesulitan membayar utangnya saat jatuh tempo kemungkinan besar perusahaan tersebut dalam kondisi financial distress (P.A \& Marbun, 2016).

H4: Ada pengaruh positif signifikan current ratio terhadap financial distress.

Debt to assets ratio adalah pengukuran aktiva yang dibebankan oleh utang perusahaan (Kasmir, 2016). DAR yang tinggi menunjukkan modal yang ditanggung oleh utang akan meningkat banyak dan kewajiban untuk membayar pinjaman beserta pajak bunga atas pinjamannya juga semakin tinggi sehingga mengakibatkan perusahaan mengalami gagal bayar yang berdampak pada financial distress (Sunaryo, 2021).

H5: Ada pengaruh positif signifikan debt to assets ratio terhadap financial distress.

Managerial ownership yaitu kapasitas saham milik internal perusahaan seperti manajer dan dewan direksi (Nurbaiti et al., 2021). Managerial ownership dalam kapasitas besar diharapkan mampu menyatukan tujuan antara manajer dengan pemilik perusahaan sehingga dapat mencegah kesulitan keuangan, sedangkan dalam jumlah kecil dapat membuat terjadinya perbedaan tujuan antara manajer dengan pemilik perusahaan sehingga financial distress pada perusahaan dapat terjadi (Masita \& Purwohandoko, 2020).

H6: Ada pengaruh positif signifikan managerial ownership terhadap financial distress.

Institutional ownership merupakan kapasitas saham yang dimiliki oleh lembaga yang bukan individu (Masita \& Purwohandoko, 2020). Institutional ownership dengan kapasitas besar diharapkan pengendalian perusahaan semakin ketat agar dapat menyusutkan konflik dan menekan biaya keagenan sehingga kesulitan keuangan perusahaan dapat dihindari (Md-Rus et al., 2013).

H7: Ada pengaruh positif signifikan institutional ownership terhadap financial distress.

\section{METODE PENELITIAN}

Penelitian yang digunakan adalah konklusif kausal, tujuannya untuk menguji hipotesis spesifik, menguji hubungan spesifik serta untuk mendapatkan bukti hubungan sebab akibat antara 
profitabilitas, aktivitas, sales growth, likuiditas, leverage, managerial ownership dan institutional ownership terhadap financial distress. Data penelitian ini menggunakan data kuantitatif dari sumber data sekunder yaitu situs resmi perusahaan dan website idx.co.id. Populasinya yaitu sektor industri perdagangan, jasa, dan investasi yang terdaftar di BEI tahun 2014-2018. Sampel diambil dengan menggunakan metode purposive sampling, dengan kriteria pemilihan sampel antara lain: perusahaan harus selalu go public selama tahun 2014-2018; perusahaan memiliki laporan keuangan tahunan tercatat selama tahun 2014-2018; dan perusahaan dengan EPS negatif selama dua tahun beruntun. Berdasarkan kriteria tersebut, terpilih sebanyak 16 perusahaan sampel.

\section{HASIL DAN PEMBAHASAN}

\section{Statistik Deskriptif}

Analisis statistik deskriptif meliputi variabel penelitian yaitu jumlah sampel, nilai terkecil, nilai terbesar, rata-rata sampel, dan standar deviasi dari masing-masing variabel. Tabel 1 menunjukkan hasil perhitungan statistik deskriptif:

Tabel 1. STATISTIK DESKRIPTIF

\begin{tabular}{|c|c|c|c|c|c|}
\hline Variabel & $\mathbf{N}$ & Min & Max & Mean & Std. Dev \\
\hline FD & 80 & .00 & 1.00 & .2250 & .42022 \\
\hline ROA & 80 & -.56 & .23 & .0086 & .09774 \\
\hline TATO & 80 & .06 & 2.77 & .6791 & .62486 \\
\hline SG & 80 & -.70 & 4.66 & .1874 & .71231 \\
\hline $\mathrm{CR}$ & 80 & .27 & 19.88 & 2.6449 & 3.31642 \\
\hline DAR & 80 & .07 & 1.92 & .5258 & .33705 \\
\hline MAN $_{\text {OWN }}$ & 80 & .00 & .59 & .1751 & .18118 \\
\hline $\mathrm{INS}_{\text {OWN }}$ & 80 & .26 & .85 & .5588 & .17799 \\
\hline Valid N & 80 & & & & \\
\hline
\end{tabular}

\section{Uji Keseluruhan Model}

Overall Model Fit digunakan sebagai pengujian model data fit atau tidak, tujuannya untuk melihat kenaikan variabel independen pada model bisa memerbaiki model atau tidak. Hasil dari uji keseluruhan model menunjukkan nilai -2 Log likelihood yang belum dijumlah dengan variabel independen menunjukkan nilai sebesar 85.574 dan yang sudah dimasukkan variabel bebas menunjukkan nilai yang berkurang yaitu sebesar 39.401. Nilai -2 Log likelihood menurun sebesar 45.905. Pada tabel chi square df sebesar 7 (80-73) diperoleh nilai sebesar 14.067 dan angka ini signifikan secara statistik. Hal ini menunjukkan nilai -2 Log likelihood $45.905>14.067$ yang artinya variabel independen yang ditambahkan pada model bisa memerbaiki model.

\section{Koefisien Determinasi}

Nagelkerke's $R$ Square digunakan sebagai pengukuran besarnya jumlah variabel independen yang bisa menjelaskan varibel dependen. Hasil uji menunjukkan nilai Nagelkerke's $R$ Square 0.666 atau $66.6 \%$ hal tersebut bermakna varibel independen bisa menggambarkan variabel dependen sebesar $66.6 \%$ dan sisanya $33.4 \%$ dipengaruhi variabel lain di luar model.

\section{Uji Kelayakan Model}

Uji Hosmer and Lemeshow's Goodness of Fit digunakan sebagai uji hipotesis atas data yang terbukti sesuai dengan model, dan model tersebut dapat dikatakan layak. Hasil uji menjelaskan nilai chi square sebesar 10.831 dan probabilitas signifikansi 0.211. Artinya tidak terdapat perbedaan dan model dapat diterima karena signifikansi 0.211 lebih besar dari 0.05 .

\section{Matrik Klasifikasi}

Matrik klasifikasi digunakan untuk menghitung estimasi nilai prediksi dari model regresi dalam mengklasifikasikan kriteria perusahaan dengan kondisi financial distress dan perusahaan non 
Elyia Rosiana Savitri \& Purwohandoko Purwohandoko. Analisis Pengaruh Financial Indicators dan Ownership Structure untuk Memprediksi Kondisi Financial Distress (Studi pada Sektor Industri Perdagangan, Jasa, dan Investasi yang Terdaftar di BEI Tahun 2014-2018

financial distress. Ketika tingkat keakuratan semakin besar, maka semakin baik model dalam memprediksi kesulitan keuangan. Tabel 2 menunjukkan hasil observed perusahaan non financial distress berjumlah 62, sedangkan perusahaan dengan kondisi financial distress berjumlah 18. Kolom predicted menunjukkan bahwa 60 perusahaan tidak mengalami kondisi financial distress dengan keakuratan $96.8 \%$ (60/62) dan perusahaan yang mengalami financial distress sebanyak 12 dengan keakuratan sebesar 66.7\% (12/18). Model ini memiliki ketepatan klasifikasi total 90.0\%.

Tabel 2.

TABEL KLASIFIKASI

\begin{tabular}{lccccc}
\hline & Observed & \multicolumn{2}{c}{$\begin{array}{c}\text { Predicted } \\
\text { Financial Distress }\end{array}$} & $\begin{array}{c}\text { Percentage } \\
\text { Correct }\end{array}$ \\
\hline Step 1 & FD & Non FD & 60 & 2 & 96.8 \\
& Non FD & FD & 66.7 \\
& Overall Percentage & & 12 & 90.0 \\
\hline
\end{tabular}

Sumber: Output SPSS

\section{Estimasi Parameter dan Interpretasinya}

Penelitian ini menguji hipotesis indikator keuangan antara lain return on assets, total assets turnover, sales growth, current ratio, dan debt to assets ratio. Ownership structure yaitu managerial ownership dan institutional ownership. Variabel-variabel independen tersebut digunakan untuk menguji seberapa besar tingkat pengaruh terhadap variabel dependen. Uji regresi logistik digunakan dalam penelitian ini dan pengaruhnya diperlihatkan pada tabel Variables in The Equation kolom signifikansi. Apabila nilai signifikansi $<0.05$ atau $<5 \%$ artinya variabel independen berpengaruh terhadap financial distress begitu pun sebaliknya variabel independen yang tidak memiliki pengaruh dengan financial distress memiliki nilai signifikansi $>0.05$ atau $>5 \%$. Model hasil uji regresi logistik pada persamaan (9).

$\operatorname{Ln}=\frac{p}{1-p} \times=-6.410+0.539 C R+14.612 D A R+e$

Tabel 3.

VARIABLES IN THE EQUATION

\begin{tabular}{lrc}
\hline \multicolumn{1}{c}{ Variabel } & B & Sig. \\
\hline ROA & 15.601 & .096 \\
TATO & -1.769 & .207 \\
SG & -.236 & .762 \\
CR & .539 & .045 \\
DAR & 14.612 & .001 \\
KEPMAN & -3.179 & .458 \\
KEPINS & -5.513 & .275 \\
Constant & -6.410 & .116 \\
\hline Sumber: SPSS (2021, data diolah) &
\end{tabular}

\section{Pengaruh Return On Assets terhadap Financial Distress}

Return on assets tidak terbukti berpengaruh signifikan dengan financial distress. Riset ini didukung oleh Rizkyana et al. (2021). Tingginya nilai ROA mengindikasikan bahwa perusahaan tidak memiliki kecukupan dana dalam mengelola asetnya dan sebagian laba yang diperoleh perusahaan berasal dari utang (Azizah et al., 2018). Penelitian ini didukung data perusahaan Elang Mahkota Teknologi Tbk tahun 2015 yang memiliki nilai ROA tinggi sebesar 10.52\% dan terbukti mengalami kesulitan keuangan. Sedangkan nilai ROA terendah adalah perusahaan Bakrie \& Brothers Tbk pada tahun 2016 sebesar $-55.38 \%$ namun tidak terindikasi mengalami financial distress. Hal ini menunjukkan perusahaan tidak efektif dalam mengelola asetnya. Hasil penelitian ini menolak $d u$ pont theory yang memberikan penjelasan mengenai hubungan total pendapatan dan total aset sebagai cerminan kinerja keuangan perusahaan. Ketidakmampuan perusahaan dalam mengatur pemulihan pendapatan membuat 
perusahaan mengalami kerugian sehingga kesulitan keuangan tidak dapat dihindari (Prianto \& Amboningtyas, 2017). Penelitian ini memberikan implikasi teoritis bahwa perusahaan tidak perlu melihat penurunan dan kenaikan nilai ROA karena tidak memengaruhi kondisi financial distress. Implikasi praktisnya perusahaan harus memaksimalkan laba agar kemungkinan kesulitan keuangan dapat dihindari.

\section{Pengaruh Total Assets Turnover terhadap Financial Distress}

Total assets turnover tidak terbukti memiliki pengaruh signifikan pada financial distress. Sejalan dengan Kholisoh \& Dwiarti (2020) dan Restianti \& Agustina (2018). Penurunan biaya yang dikeluarkan dan peningkatan penjualan menunjukkan peningkatan keuntungan yang didapat sehingga perputaran aset ikut meningkat, sebaliknya apabila perusahaan kurang efektif dalam melakukan efisiensi biaya pada setiap penjualan maka laba yang diperoleh akan menurun (Arini et al., 2021). Data yang mendukung adalah data perusahaan Bakrie \& Brothers Tbk dengan nilai TATO mengalami penurunan berturut-turut tiap tahun yaitu dari tahun 2014-2018 dan terindikasi dalam kondisi financial disress. Namun, data perbandingan lain yaitu perusahaan Saratoga Investama Sedaya Tbk dan Erajaya Swasembada Tbk pada tahun 2018 Saratoga Investama Sedaya Tbk memiliki nilai TATO terendah yaitu 5.70\% terindikasi tidak mengalami kondisi financial distress, dibandingkan dengan perusahaan Erajaya Swasembada Tbk mempunyai nilai TATO tertinggi pada tahun 2018 yaitu 273.94\% yang terindikasi mengalami kondisi financial distress. Dilihat dari uraian data tersebut, jumlah nilai TATO tidak memengaruhi kondisi financial distress.

Hasil penelitian ini menolak du pont theory yang menjelaskan mengenai pemulihan total aset dapat menjadi tolok ukur kinerja keuagan perusahaan. Aset yang dikelola perusahaan tidak efektif yang mengakibatkan pengembalian dana mengalami penurunan yang berdampak pada kesulitan keuangan perusahaan (Prianto \& Amboningtyas, 2017). Implikasi teoritis yang dapat dilakukan perusahaan tidak perlu melihat tingkat penurunan dan kenaikan TATO karena jumlah nilai TATO tidak memengaruhi perusahaan mengalami financial distress. Implikasi praktisnya perusahaan perlu melakukan ketepatan perhitungan biaya pada setiap penjualan agar perusahaan mendapatkan laba yang tinggi dibandingkan dengan biaya yang dikeluarkan.

\section{Pengaruh Sales Growth terhadap Financial Distress}

Sales growth tidak terbukti ada pengaruh signifikan dengan financial distress. Penelitian ini didukung oleh Suryani (2020). Sales growth tidak bisa digunakan sebagai pengukuran tingkat kesulitan keuangan di suatu perusahaan karena pendapatan selain penjualan yang diperoleh perusahaan mampu menutup biaya kebutuhan lain sehingga kondisi financial distress dapat dihindari (Dianova \& Nahumury, 2019). Penelitian ini didukung oleh data dari perusahaan Erajaya Swasembada Tbk pada tahun 2014 perusahaan Erajaya Swasembada Tbk memiliki nilai sales growth sebesar $13.55 \%$ dan tahun 2015 mengalami kenaikan sebesar $38.45 \%$ dengan keuntungan yang tinggi sebesar 5.556.184.639.967 rupiah. Begitu juga dengan perusahaan Intraco Penta Tbk memiliki nilai sales growth sebesar -34.99\% pada tahun 2014 dan mengalami kenaikan sebesar $-20.77 \%$ pada tahun 2015 , namun keuntungan yang diperoleh menurun sebesar -347.079.000.000 rupiah yang disebabkan oleh penjualan dan utang yang tinggi. Sehingga dapat dikatakan bahwa kenaikan dan penurunan keuntungan penjualan yang diperoleh perusahaan tidak memengaruhi kondisi financial distress.

Hasil penelitian ini menolak $d u$ pont theory yang menjelaskan mengenai besarnya keuntungan yang akan diperoleh perusahaan apabila meingkatkan kapasitas penjualannya sehingga kondisi keuangan perusahaan dapat terjaga dengan baik (Prianto \& Amboningtyas, 2017). Rendahnya kapasitas penjualan perusahaan mengakibatkan kerugian yang siginifikan dan berdampak pada kondisi keuangan perusahaan yang menurun (Dianova \& Nahumury, 2019). Implikasi teoritis bagi perusahaan yaitu tidak perlu memerhatikan penurunan dan kenaikan nilai sales growth karena besar kecilnya nilai sales growth tidak memengaruhi terjadinya financial distress. Implikasi praktisnya perusahaan agar terus meningkatkan skala penjualan tiap tahun agar kinerja perusahaan meningkat dan terhindar dari kesulitan keuangan. 
Elyia Rosiana Savitri \& Purwohandoko Purwohandoko. Analisis Pengaruh Financial Indicators dan Ownership Structure untuk Memprediksi Kondisi Financial Distress (Studi pada Sektor Industri Perdagangan, Jasa, dan Investasi yang Terdaftar di BEI Tahun 2014-2018

\section{Pengaruh Current Ratio terhadap Financial Distress}

Current ratio terbukti ada pengaruh positif signifikan terhadap financial distress. Hasil sejalan dengan Sukmawati et al. (2020). Pengaruh ini menunjukkan suatu perusahaan dikatakan mengalami kondisi financial distress apabila nilai current ratio semakin kecil maka kecakapan perusahaan dalam membayar utang jangka pendeknya akan semakin menurun dan mengalami dari gagal bayar, sebaliknya apabila nilai current ratio perusahaan semakin meningkat perusahaan mampu memenuhi utang jangka pendeknya agar dapat terbebas dari kondisi financial distress (Septyanto \& Welandasari, 2020). Penelitian ini dibuktikan dengan data dari perusahaan Bakrie \& Brothers Tbk yang memiliki nilai current ratio terkecil sebesar $27.01 \%$ yang merupakan jumlah utang lancar perusahaan Bakrie \& Brothers Tbk dan diantaranya dapat membayar semua utangnya menggunakan semua aset lancarnya. Total aset lancar Bakrie \& Brothers Tbk sebesar 3.140.063.000.000 rupiah, sedangkan jumlah utang lancarnya sebesar 11.627.098.000.000 rupiah. Banyaknya jumlah utang lancar dibandingkan dengan total aset lancar yang dimiliki, maka Bakrie \& Brothers Tbk tidak mampu membayar utang keseluruhan dengan menggunakan aset lacar yang dimiliki dan terbukti bahwa Bakrie \& Brothers Tbk tergolong perusahaan dengan kondisi financial distress.

Hasil penelitian ini mendukung trade off theory yang menjelaskan mengenai penambahan komposisi ekuitas dan nilai utang sebagai penghematan biaya pajak akan menguntungkan perusahaan (Modigliani \& Miller, 1958). Perusahaan yang dapat menyeimbangkan manfaat dan risiko nilai utang maka pemakaian liabilitas dapat tercapai secara optimal dan kesulitan keuangan dapat dihindari (Oktasari, 2020). Implikasi teoritis perusahaan harus mengamati nilai current ratio dengan meningkatkan akun aset lancar karena besar kecilnya nilai current ratio memengaruhi terjadinya financial distress. Implikasi praktisnya perusahaan dapat melakukan pemenuhan utang jangka pendeknya agar dapat menghindari fiancial distress.

\section{Pengaruh Debt to Assets Ratio terhadap Financial Distress}

Debt to assets ratio terbukti ada pengaruh positif signifikan terhadap financial distress. DAR menunjukkan skala biaya berasal dari utang untuk mendanai aktiva (Kasmir, 2016). Teori struktur modal menjelaskan mengenai besarnya jumlah utang yang dimiliki perusahaan akan membuat beban bunga yang dibayar akan semakin bengkak sehingga jumlah pembayaran pajak berkurang, keadaan tersebut membuat aliran dana perusahaan semakin bertambah dan kemungkinan financial distress akan berkurang (Prayuningsih et al., 2021). Penelitian ini didukung oleh Setiawan \& Fitria (2020) dan Rizkyana et al. (2021). Data pendukungnya adalah data perusahaan Electronic City Indonesia Tbk tahun 2016 memiliki nilai DAR paling rendah diantara perusahaan sampel yaitu 8.18\% dan tidak terindikasi perusahaan mengalami kondisi financial distress. Namun, data perusahaan Bakrie \& Brothers Tbk tahun 2016 dengan nilai DAR tertinggi diantara perusahaan sampel yaitu $192.28 \%$ dan terindikasi mengalami financial distress. Data tersebut menjelaskan bahwa tinggi rendahnya nilai DAR dapat memengaruhi kondisi financial distress. Hasil penelitian ini mendukung trade off theory yang menjelaskan teori struktur modal dari penambahan kapasitas utang dapat menambah keuntungan bagi perusahaan (Modigliani \& Miller, 1958). Perusahaan dapat memaksimalkan manfaat dari kapasitas utangnya sebagai pengurang pajak sehingga kemungkinan kesulitan keuangan dapat dihidari (Sugiarto \& Mahanani, 2020). Implikasi teoritis perusahaan perlu melihat nilai DAR karena peningkatan nilai yang berkala mengakibatkan perusahaan mengalami financial distress. Implikasi praktisnya perusahaan perlu meningkatkan kapasitas utang dengan mengelola secara efektif agar perusahaan mendapatkan keuntungan dari utang yang dimiliki.

\section{Pengaruh Managerial Ownership terhadap Financial Distress}

Managerial ownership tidak terbukti berpengaruh signifikan dengan financial distress. Hasil didukung oleh Putri (2019). Jumlah managerial ownership di perusahaan sangat minim yang menyebabkan perusahaan tidak memiliki suara dalam pengambilan keputusan rapat umum pemegang saham (Putri, 2019). Managerial ownership hanya dijadikan sebagai umpan dalam menarik para investor, menurut pandangan para investor apabila perusahaan memiliki saham managerial ownership maka perusahaan tersebut dikategorikan sebagai perusahaan berkualitas tinggi (Kabir et al., 2020). Penelitian ini didukung oleh data dari perusahaan Dyandra Media International Tbk tahun 2014-2015 
diketagorikan sebagai perusahaan dengan kondisi financial distress, sedangkan tahun 2017-2018 bukan kategori perusahaan terindikasi financial distress. Persentase managerial ownership tahun 2014 lebih tinggi yaitu sebesar 10.94\% dibandingkan dengan tahun 2015-2018, namun dikategorikan sebagai perusahaan dengan kondisi financial distress. Hasil uraian data membuktikan tidak adanya pengaruh managerial ownership dengan financial distress.

Hasil penelitian ini menolak agency theory yang menjelaskan bahwa managerial ownership dapat menyatukan perbedaan kepentingan yang saling bertentangan antara manajer dan pemilik perusahaan. Besarnya kapasitas managerial ownership dapat menurunkan konflik, sehingga beban biaya kerugian dapat berkurang dan kesulitan keuangan perusahaan akan menurun (Sugiarto \& Mahanani, 2020). Implikasi teoritis industri tidak perlu melihat kapasitas besarnya managerial ownership, karena besarnya managerial ownership tidak terbukti dapat mengakibatkan perusahaan mengalami financial distress. Implikasi praktisnya perusahaan perlu melakukan efektifitas dan efisiensi kinerja managerial ownership agar memberikan dampak yang baik bagi perusahaan.

\section{Pengaruh Institutional Ownership terhadap Financial Distress}

Institutional ownership tidak terbukti ada pengaruh signifikan pada financial distress. Penelitian ini didukung oleh Valentina \& Jin Fung (2020). Kepemilikan saham oleh institusi tersentralisasi dan kurang adanya peran aktif dari investor institusi untuk mengendalikan manajemen sehingga menyebabkan pengawasan saham manajemen menurun (Guo \& Platikanov, 2019). Data pendukung penelitian ini adalah data perusahaan Electronic City Indonesia Tbk tahun 2015-2016 perusahaan Electronic City Indonesia Tbk memiliki nilai presentase institutional ownership yang sama yaitu sebesar $45.55 \%$ dan bukan kategori perusahaan terindikasi financial distress, sedangkan pada tahun 2017 perusahaan Electronic City Indonesia Tbk termasuk kategori perusahaan dengan kondisi financial distress. Dari penjelasan data tersebut, institutional ownership tidak memengaruhi kondisi kesulitan keuangan perusahaan. Hasil penelitian ini menolak agency theory, bahwa institutional ownership memiliki fungsi sebagai pegawas manajemen perusahaan. Besarnya kapasitas institutional ownership akan membuat investor melakukan pengawasan yang optimal terhadap kinerja manajemen, sehingga dapat memaksimalkan kinerja manajemen dan kesulitan keuangan dapat dihindari (Masita \& Purwohandoko, 2020). Implikasi teoritis perusahaan tidak perlu melihat kapasitas besarnya institutional ownership, karena besarnya institutional ownership tidak terbukti bisa memengaruhi financial distress. Implikasi praktisnya perusahaan perlu melakukan efektifitas dan efisiensi kinerja institutional ownership agar bermanfaat bagi perusahaan.

\section{KESIMPULAN}

Kesimpulan penelitian ini adalah ada pengaruh positif signifikan current ratio dan debt to assets ratio terhadap financial distress. Penyelesaian yang dapat dilakukan sektor industri perdagangan, jasa, dan investasi yang memiliki EPS negatif beruntun tiap tahunnya adalah dengan melunasi kewajiban jangka pendeknya dalam kurun waktu yang telah ditetapkan dan memaksimalkan manfaat dari kapasitas utang sebagai pengurang pajak sehingga kesulitan keuangan pada perusahaan dapat dihindari. Keterbatasan yang dimiliki penelitian ini adalah variabel yang digunakan kurang bervariasi, diharapkan penelitian selanjutnya menambah jumlah variabel yang digunakan misalnya corporate governance, firm size, return on equity, quick ratio, dan inflation dalam mengukur perusahaan financial distress agar data lebih bervariasi.

\section{DAFTAR PUSTAKA}

Alifah, N., \& Trisilo, R. B. (2021). Pengaruh ROA, CR, DR, SG, TATO terhadap Financial Distress pada Perusahaan Publik Property, Real Estate, dan Building Construction di BEI Tahun 20142018. Jurnal Ekonomi dan Bisnis Universitas Trilogi, 2(1), 1-20.

Ananto, R. P. (2020). Penggunaan Model Springate untuk Mendeteksi Penurunan Kinerja Keuangan (Financial Distress) Sektor Pertambangan di Bursa Efek Indonesia. Jurnal Akuntansi Keuangan 
Elyia Rosiana Savitri \& Purwohandoko Purwohandoko. Analisis Pengaruh Financial Indicators dan Ownership Structure untuk Memprediksi Kondisi Financial Distress (Studi pada Sektor Industri Perdagangan, Jasa, dan Investasi yang Terdaftar di BEI Tahun 2014-2018

Dan Bisnis, 13(1), 61-70. https://doi.org/https://doi.org/10.35143/jakb.v13i1.3607

Anggriani, P., \& Rahim, R. (2021). Pengaruh Mekanisme Tata Kelola Perusahaan dan Political Connection Terhadap Financial Distress. Jurnal Penelitian Ilmu Manajemen, 6(1), 64-77. https://doi.org/http://dx.doi.org/10.30736\%2Fjpim.v6i1.647

Arini, S. A., Samrotun, Y. C., \& Masitoh, E. (2021). Determinant of Financial Ratio Analysis to Financial Distress. Jambura Science of Management, 3(1), 26-35. https://doi.org/http://dx.doi.org/10.37479/jsm.v3i1.6962

Azizah, U., I Wayan, R., \& L.G.P Sri Eka, J. (2018). Pengaruh Good Corporate Governance, Leverage, Profitabilitas, dan Likuiditas Terhadap Financial Distress. Jurnal Ekonomi, Bisnis Dan Ekonomi, 29-50.

Baklouti, N., Gautier, F., \& Affes, H. (2016). Corporate Governance and Financial Distress of European Commercial Banks. Journal of Business Studies Quarterly, 7(3), 75-96.

Bank Indonesia. (2018). Laporan Perekonomian Ekonomi 2018. https://www.bi.go.id/id/publikasi/laporan/Pages/LPI_2018.aspx/Diakses pada 20 Juli 2020

De Andrés, J., Landajo, M., \& Lorca, P. (2009). Flexible Quantile-based Modeling of Bivariate Financial Relationships: The Case of ROA Ratio. Expert Systems with Applications, 36(5), 8955-8966. https://doi.org/https://doi.org/10.1016/j.eswa.2008.11.021

Dianova, A., \& Nahumury, J. (2019). Investigating the Effect of Liquidity, Leverage, Sales Growth and Good Corporate Governance on Financial Distress. Journal of Accounting and Strategic Finance, 2(2), 143-156. https://doi.org/https://doi.org/10.33005/jasf.v2i2.49

Dipietre, D., Fuchs, L., Tubbs, R., \& Green, B. (1997). Critical Control Points : Managing Assets , Expenses and Leverage. Purdue University, 45-60.

Dirman, A. (2020). Financial Distress: The Impacts of Profitability, Liquidity, Leverage, Firm Size, and Free Cash Flow. International Journal of Business, Economics and Law, 22(1), 17-25.

Diwanti, N. S., \& Purwanto. (2020). The Influence of Financial Ratios and Good Corporate Governance Towards Financial Distress on Islamic Banks in Indonesia. Journal of Management Studies, 5(1), 1-17. https://doi.org/http://dx.doi.org/10.33021/firm.v5i1.984

Elkamhi, R., Ericsson, J., \& Parsons, C. A. (2012). The cost and timing of financial distress. Journal of Financial Economics, $105(1), \quad 62-81$. https://doi.org/https://doi.org/10.1016/j.jfineco.2012.02.005

Grice, J. S., \& Ingram, R. W. (2001). Test of The Generalizability of Altman's Bankruptcy Predication Model. Journal of Business Research, 54, 53-61. https://doi.org/https://doi.org/10.1016/S0148-2963(00)00126-0

Guo, L., \& Platikanov, S. (2019). Institutional Ownership and Corporate Governance of Public Companies in China. Pacific-Basin Finance Journal, 57, 101-180. https://doi.org/https://doi.org/10.1016/j.pacfin.2019.101180

Handriani, E., Ghozali, I., \& Hersugodo, H. (2021). Corporate Governance on Financial Distress: Evidence from Indonesia. Management Science Letters, 11, 1833-1844. https://doi.org/http://dx.doi.org/10.5267/j.msl.2021.1.020

Jensen, M. C., \& Meckling, W. H. (1976). Theory Of Firm: Managerial Behavior, Agency Costs and 
Ownership Structure. Journal of Financial Economics, 72(10), 1671-1696. https://doi.org/https://doi.org/10.1016/0304-405X(76)90026-X

Jiming, L., \& Weiwei, D. (2011). An Emprical Study on the Corporate Financial Distress Prediction Based on Logistic Model: Evidence from China's Manufacturing Industry. International Journal of Digital Content Technology and Its Applications, 5(6), 368-379. https://doi.org/http://dx.doi.org/10.4156/jdcta.vol5.issue6.44

Juliana Lelu, E., \& Thamrin, H. (2021). The Influence of Corporate Governance on Potential Financial Distress on Transportation Companies listed on the Indonesia Stock Exchange for the period 2013-2017. Journal of Sosial Science, 2(1), 29-39. https://doi.org/https://doi.org/10.46799/jsss.v2i1.83

Kabir, M. N., Miah, M. D., Ali, S., \& Sharma, P. (2020). Institutional and Foreign Ownership vis-àvis Default Risk: Evidence From Japanese Firms. International Review of Economics and Finance, 69, 469-493. https://doi.org/https://doi.org/10.1016/j.iref.2020.05.020

Kasmir. (2016). Analisis Laporan Keuangan. Jakarta: PT Raja Grafindo Persada.

Kholisoh, S. N., \& Dwiarti, R. (2020). The Analysis of Fundamental Variables and Macro Economic Variables in Predicting Financial Distress. Management Analysis Journal, 9(1), 81-90. https://doi.org/https://doi.org/10.15294/maj.v9i1.36395

Liahmad, Rusnindita, K., Utami, Y. P., \& Sitompul, S. (2021). Financial Factors and Non-Financial to Financial Distress Insurance Companies That Listed in Indonesia Stock Exchange. Budapest International Research and Critics Institute-Journal (BIRCI-Journal), 4(1), 1305-1312. https://doi.org/https://doi.org/10.33258/birci.v4i1.1757

Liu, B., Ju, T., Bai, M., \& Yu, C. F. (Jeffrey). (2021). Imitative Innovation and Financial Distress Risk: The Moderating Role of Executive Foreign Experience. International Review of Economics and Finance, 71, 526-548. https://doi.org/https://doi.org/10.1016/j.iref.2020.09.021

Lumbantobing, R. (2020). The Effect of Financial Ratios on the Possibility of Financial Distress in Selected Manufacturing Companies Which Listed in Indonesia Stock Exchange. Advances in Economics, Business and Management Research, 132, 60-63. https://doi.org/https://dx.doi.org/10.2991/aebmr.k.200331.014

Mamduh, M. H., \& Abdul, H. (2016). Analisis Laporan Keuangan (Edisi 5). Yogyakarta: UPP STIM YKPN.

Masita, A., \& Purwohandoko. (2020). Analisis Pengaruh Rasio Keuangan, Kepemilikan Manajerial, dan Kepemilikan Institusional terhadap Financial Distress pada Perusahaan Sektor Perdagangan, Jasa, dan Investasi yang Terdaftar di BEI Tahun 2015-2018. Jurnal Ilmu Manajemen, 8(3), 894-908. https://doi.org/http://dx.doi.org/10.26740/jim.v8n3.p894-908

Md-Rus, R., Mohd, K. N. T., Latif, R. A., \& Alassan, Z. N. (2013). Ownership Structure and Financial Distress. Journal of Advanced Management Science, 1(4), 363-367. https://doi.org/http://dx.doi.org/10.12720/joams.1.4.363-367

Modigliani, F., \& Miller, M. H. (1958). The Cost of Capital, Corporation Finance and the Theory of Investment. The American Economic Review, 48(3), 261-267. https://www.jstor.org/stable/1809766

Muis, M. A. (2017). Analisis Pengaruh Return on Assets, Net Profit Margin Return on Equity, Debt to Equity Ratio, dan Debt to Asset Ratio untuk Memprediksi Financial Distress pada Perusahaan 
Elyia Rosiana Savitri \& Purwohandoko Purwohandoko. Analisis Pengaruh Financial Indicators dan Ownership Structure untuk Memprediksi Kondisi Financial Distress (Studi pada Sektor Industri Perdagangan, Jasa, dan Investasi yang Terdaftar di BEI Tahun 2014-2018

Manufaktur yang Terdaftar di Bursa Efek Indonesia Periode 2014-2017. Jurnal Manajemen Bisnis, 9(1), 51-61. https://doi.org/http://dx.doi.org/10.31000/jmb.v9i1.2304.g1604

Najwa, S. B. I. (2020). Determinants of Capital Structure in Manufacturing Sector: Evidence From Financial Distress Firms in Malaysia (2010-2018). Universiti Teknologi Mara, 21(1), 1-9. https://doi.org/http://ir.uitm.edu.my/id/eprint/32368

Noviandri, T. (2014). Peranan Analisis Rasio Keuangan dalam Memprediksi Kondisi Financial Distress Perusahaan Sektor Perdagangan. Jurnal Ilmu Manajemen, 2, 1655-1665.

Nugrahanti, Y. W., Sutrisno, T., Rahman, A. F., \& Mardiati, E. (2020). Do Firm Characteristics, Political Connection and Corporate Governance Mechanism Affect Financial Distress? (Evidence from Indonesia). International Journal of Trade and Global Markets, 13(2), 220250 .

Nurbaiti, A., Lestari, T. U., \& Thayeb, N. A. (2021). Pengaruh Corporate Governance, Financial Distress, dan Ukuran Perusahaan Terhadap Integritas Laporan Keuangan. Jurnal Ilmiah MEA (Manajemen, Ekonomi , Dan Akuntansi), 5(1), 758-771.

Oktasari, D. P. (2020). The Effect of Liquidity, Leverage and Firm Size of Financial Distress. East African Scholars Multidisciplinary Bulletin, 3(9), 293-297. https://doi.org/http://dx.doi.org/10.36349/easmb.2020.v03i09.002

P.A, M., \& Marbun, D. (2016). Pengaruh Current Ratio dan Debt to Equity Ratio Terhadap Return on $\begin{array}{llll}\text { Assets. Widyakala } & \text { Journal, 23-28. }\end{array}$ https://doi.org/https://doi.org/10.36262/widyakala.v3i0.21

Prayuningsih, I. G. A., Endiana, I. D. M., Pramesti, I. G. A. A., \& Mirah, N. P. A. (2021). Pengaruh Profitabilitas, Likuiditas, Leverage, Rasio Aktivitas dan Pertumbuhan Penjualan untuk Memprediksi Kondisi Financial Distress. Karya Riset Mahasiswa Akuntansi, 1(Vol 1 No 1 (2021): Edisi Pebruari), 137-147.

Prianto, E., \& Amboningtyas, D. (2017). Analisis Du Pont System untuk Menilai Kinerja Keuangan Perusahaan (Studi pada PT. Mayora Indah Tbk, PT. Delta Djakarta Tbk, dan PT. Indofood Sukses Makmur Tbk Periode Tahun 2010-2015). Jurnal Ekonomika Dan Bisnis Universitas Pandanaran, 3(3), 1-6.

Putri, R. D. (2019). Analisis Pengaruh Pertumbuhan Penjualan dan Kepemilikan Manajerial terhadap Kondisi Financial Distress Pada Perusahaan Manufaktur yang Ada di Indonesia. Jurnal Sosial Dan Ilmu Ekonomi, 4, 54-63. https://doi.org/http://dx.doi.org/10.36665/jusie.v4i01.189

Restianti, T., \& Agustina, L. (2018). Accounting Analysis Journal The Effect of Financial Ratios on Financial Distress Conditions in Sub Industrial Sector Company. Accounting Analysis Journal, 7(1), 25-33. https://doi.org/https://doi.org/10.15294/aaj.v7i1.18996

Rizkyana, A. W., Fadila, A., \& Pinem, D. B. (2021). Identifikasi Potensi Financial Distress pada Industri Pertambangan di Indonesia. Jurnal Apresiasi Ekonomi, 9(1), 78-89. https://doi.org/https://doi.org/10.31846/jae.v9i1.336

Sagho, M., \& Merkusiwati, N. (2015). Penggunaan Metode Altman Z-Score Modifikasi untuk Memprediksi Kebangkrutan Bank yang Terdaftar di Bursa Efek Indonesia. E-Jurnal Akuntansi Universitas Udayana, 11(3), 730-742.

Septyanto, D., \& Welandasari, N. F. (2020). Effect Of Current Ratio, Debt to Asset Ratio, and Return to Success on Financial Distress in Indonesia Stock Exchange. Jurnal Akuntansi, 231-247. 
Setiawan, R., \& Fitria, Y. (2020). Pengaruh Debt Ratio, Current Ratio dan Return on Assets Terhadap Financial Distress pada Perusahaan Manufaktur Sektor Industri Dasar dan Kimia yang Terdaftar di Bursa Efek Indonesia. Jurnal Akuntansi Dan Keuangan, 17(2), 226-230. https://doi.org/http://dx.doi.org/10.29264/jakt.v17i2.8050

Setkab.go.id. (2019). Tertinggi Sejak 2014, BPS: Ekonomi Indonesia 2018 Tumbuh 5,17 Persen. https://setkab.go.id/tertinggi-sejak-2014-bps-ekonomi-indonesia-2018-tumbuh-517persen/Diakses pada 22 Juli 2020

Sudana, I. M. (2011). Manajemen keuangan Perusahaan: Teori \& Praktik (N. I. Sallama (ed.); 2nd ed.). Jakarta: Erlangga.

Sudjiman, A. A. J. S., \& Sudjiman, L. S. (2020). Investigating Effect of Liquidity, Leverage and Sales Growth on Financial Distress. Jurnal Ekonomis, 13(2), 3-18.

Sugiarto, \& Mahanani, S. (2020). Effect Of Profitability, Leverage, Liquidity, and Activity Against Financial Distress Conditions. Ekbis: Jurnal Ekonomi Dan Bisnis, 4(2), 456-468. https://doi.org/https://doi.org/10.14421/EkBis.2020.4.2.1275

Sukmawati, N. K. D., Widnyana, I. W., \& Sukadana, I. W. (2020). Analisis Kinerja Keuangan dalam Memprediksi Kondisi Financial Distress pada Perusahaan Perbankan yang Terdaftar di Bursa Efek Indonesia Tahun 2015-2017. Values: Jurnal Pengabdian Kepada Masyarakat, 1(3), 244251.

Sunaryo, D. (2021). Identification of Financial Distress with Company Size As a Moderating Variables in Southeast Asia Property and Real Estate Industry. International Journal of Science, Technology \& Management, 2(1), 349-363. https://doi.org/https://doi.org/10.46729/ijstm.v2i1.115

Suryani, S. (2020). Pengaruh Profitabilitas, Leverage, Sales Growth dan Ukuran Perusahaan terhadap Financial Distress. Jurnal Online Insan Akuntan, 5(2), 229-244. https://doi.org/https://doi.org/10.51211/joia.v5i2.1440

Syofyan, A., \& Herawaty, V. (2019). Pengaruh Good Corporate Governance Terhadap Financial Distress dengan Kualitas Audit Sebagai Pemoderasinya. Prosiding Seminar Nasional Cendekiawan, 2015, 2.38.2-2.38.7. https://doi.org/http://dx.doi.org/10.25105/semnas.v0i0.5827

Valentina, V., \& Jin Fung, T. (2020). Financial Distress: Rasio Keuangan dan Struktur Kepemilikan pada Perusahaan Non-Keuangan. Jurnal Bisnis Dan Akuntansi, 22(2), 347-360. https://doi.org/https://doi.org/10.34208/jba.v22i2.818 